\title{
Women decision-making capacity and intimate partner violence among women in sub-Saharan Africa
}

\author{
Bright Opoku Ahinkorah ${ }^{1 *}$, Kwamena Sekyi Dickson² and Abdul-Aziz Seidu²
}

\begin{abstract}
Background: Violence against women is a common form of human rights violation, and intimate partner violence (IPV) appears to be the most significant component of violence. The aim of this study was to examine the association between women decision-making capacity and IPV among Women in Sub-Saharan Africa. The study also looked at how socio-demographic factors also influence IPV among Women in Sub-Saharan Africa.
\end{abstract}

Methods: The study made use of pooled data from most recent Demographic and Health Survey (DHS) conducted from January 1, 2010, and December 3, 2016, in 18 countries in Sub-Saharan Africa. For the purpose of the study, only women aged 15-49 were used $(N=84,486)$. Univariate and multivariate logistic regression models were used to investigate the relationship between the explanatory variables and the outcome variable.

Results: The odds of reporting ever experienced IPV was higher among women with decision-making capacity $[A O R=1$. 35; $\mathrm{Cl}=1.35-1.48]$. The likelihood of experiencing IPV was low among young women. Women who belong to other religious groups and Christians were more likely to experience IPV compared to those who were Muslims [AOR = 1.73; $\mathrm{Cl}=1.65-1.82]$ and $[\mathrm{AOR}=1.87 ; \mathrm{Cl}=1.72-2.02]$ respectively. Women who have partners with no education $[\mathrm{AOR}=1.11$; $\mathrm{Cl}=1.03-1.20]$, those whose partners had primary education $[\mathrm{AOR}=1.34 ; \mathrm{Cl}=1.25-1.44]$ and those whose partners had secondary education $[A O R=1.22 ; \mathrm{Cl}=1.15-1.30]$ were more likely to IPV compared to those whose partners had higher education. The odds of experiencing IPV were high among women who were employed compared to those who were unemployed $[A O R=1.33 ; \mathrm{Cl}=1.28-1.37]$. The likelihood of the occurrence of IPV was also high among women who were cohabiting compared to those who were married $[A O R=1.16 ; C l=1.10-1.21]$. Women with no education $[A O R=1.37$; $\mathrm{Cl}=1.24-1.51]$, those with primary education $[\mathrm{AOR}=1.65 ; \mathrm{Cl}=1.50-1.82]$ and those with secondary education $[\mathrm{AOR}=1$. 50; $\mathrm{Cl}=1.37-1.64]$ were more likely to experience IPV compared to those with higher education. Finally, women with poorest wealth status $[A O R=1.28 ; \mathrm{Cl}=1.20-1.37]$, those with poorer wealth status $[\mathrm{AOR}=1.24 ; \mathrm{Cl}=1.17-1.32]$, those with middle wealth status $[A O R=1.27 ; \mathrm{Cl}=1.20-1.34]$ and those with richer wealth status $[A O R=1.11 ; \mathrm{Cl}=1.06-1.17]$ were more likely to IPV compared to women with richest wealth status.

Conclusion: Though related socio-demographic characteristics and women decision-making capacity provided an explanation of IPV among women in sub-Saharan Africa, there were differences in relation to how each socio-demographic variable predisposed women to IPV in Sub-Saharan Africa.

Keywords: Women, Decision-making capacity, Intimate partner violence, Sub-Saharan Africa

\footnotetext{
* Correspondence: bright.ahinkorah@stu.ucc.edu.gh

${ }^{1}$ Department of Health, Physical Education and Recreation, University of

Cape Coast, Cape Coast, Ghana

Full list of author information is available at the end of the article
} 


\section{Background}

Violence against women is a common form of human rights violation, and intimate partner violence (IPV) appears to be the most significant component of violence $[1,2]$. IPV is associated with a wide range of negative consequences for women who are abused, including loss of pregnancy and contraction of sexually transmitted infections [3]. IPV is common in all societies, but the level and rate to which it is considered acceptable differ from one country to another [4]. All over the world, Sub-Saharan African countries have recorded the highest levels of violence against women [1]. Intimate partner violence (IPV) is widespread throughout much of sub-Saharan Africa, with an overall prevalence of $36 \%$ exceeding the global average of $30 \%$ [5]. More women in Africa are subject to lifetime partner violence (45.6\%) and sexual assault (11.9\%) than women anywhere in the world [5].

IPV has adverse outcomes for women, ranging from poor psychological health to adverse reproductive health effects such as poor birth outcomes [6]. In Sub-Saharan Africa, women show several psychological disorders in response to intimate partner abuse although both men and women manifest psychological symptoms in the aftermath of a physical altercation [7]. Previous studies by Pallitto et al. [8] and Salazar and San Sebastian [9] have identified strong associations between IPV and negative pregnancy outcomes. Women who reported ever experiencing physical or sexual violence by spouses have been identified to have higher odds of unintended or unwanted pregnancies. Lifetime experience of IPV has also been associated with higher odds of having a non-live birth, thus, having a pregnancy ending in a miscarriage, induced abortion, or termination $[10,11]$. Moreover, reproductive health can be compromised in several ways, from raising the risk of STIs to threatening a pregnancy [12]. IPV is also associated with sexually transmitted infections [13] which in Africa carry significance as potential gateways to HIV infection [14]. Some of the risk factors for IPV in Africa mirror those found in other regions of the world such as excessive drinking or a past history of child abuse, or socioeconomic conditions such as unemployment. In addition, long-standing patriarchal traditions play a role.

African cultural beliefs and traditions promote men's hierarchical role in sexual relationships and especially marriage [15]. Norms surrounding violence in families also change more slowly in rural areas [16]. In sub-Saharan Africa, gender relations incorporating violence reflect the legacy of conflict and hegemony which marked the colonial period [17]. According to Boonzaier [18], economic and political transformation has actually left many men without a clear position, provoking tension in the relationships between men and women. Beliefs relating to gender roles in marriage lay the groundwork for IPV in many regions of Africa. Patriarchal beliefs are not the only explanation for partner abuse but such attitudes sustain community tolerance of IPV reducing the chance for a systemic social response [19]. In sub-Saharan Africa, a significant proportion of both men and women endorse a man's prerogative to physically discipline his wife [20] with more women than men endorsing what they view as justified abuse, such as when a wife appears to neglect the children or argues with her husband [21].

To understand the origins of intimate partner abuse in Africa, it is important to interpret the problem against the context of family life and gender roles $[17,22]$ The belief that women's sexual response must be suppressed, that she should be traded for marriage by her father, and that her husband is free to take multiple wives, sets the stage for the commodification of women and the acceptance of violence in support of a husband's effort to control [19]. In this regard, one of the key issues that seem to offer a solution to IPV is women decision making capacity, which is sometimes linked with empowerment. Empowerment is a process that gives power to the individuals who are not empowered and increases their ability to make strategic choices [23]. In line with this, women empowerment has been defined as the growth in the ability of people to make planned life choices within a context where this ability was previously denied to them [24].

Evidence suggests that, at times, women's economic or social empowerment may undermine IPV, and at times may trigger it [25, 26]. Jewkes et al. [25] theorize that as a woman begins to become empowered she may question rigid gender roles but her empowerment may not be sufficient to insulate her from the effects of such change. According to Rahman, Hoque and Makinoda [27], the likelihood of all forms of IPV increases with participation in household decision-making. Naved and Persson [28] report similar findings. These findings suggest that women's empowerment may influence their risk of IPV in complex and contradictory ways and that their risk may vary with specific forms of empowerment. On the contrary, a recent study in Bangladesh identified that women empowerment is becoming protective against IPV even though IPV rates remain high [29]. The absence of uniformity in the understanding of whether women empowerment results in or reduces IPV has not been explored among women in sub-Saharan Africa.

In the context of Sub-Saharan Africa, few studies have been conducted. One of such studies was conducted by Naved and Persson [30] where they found that women's empowerment has a strong influence on their use of reproductive and maternal health service. A recent study by Cools and Kotsadam [4] also looked at resources and IPV in Sub-Saharan Africa and found that resource inequality, both within the household and at the aggregate level, is associated with more abuse. The paucity of literature that has looked at the relationship between women empowerment, 
especially in relation to women decision-making capacity and IPV in Sub-Saharan Africa, together with the inconsistency in findings of previous studies that have looked at women empowerment and IPV in other countries, has necessitated the need for this study. With women decisionmaking capacity, constituting a key component of women empowerment, the aim of this study is to examine the association between women decision-making capacity and IPV among Women in Sub-Saharan Africa. The study also looks at how socio-demographic factors also influence IPV among Women in Sub-Saharan Africa.

\section{Methods}

Data

The study made use of pooled data from most current Demographic and Health Survey (DHS) conducted from January 1, 2010, and December 31, 2016, conducted in 18 countries in Sub-Saharan Africa. DHS is a nationwide survey collected every five-year period across low and middle-income countries. DHS focuses on maternal and child health by interviewing women of reproductive age (15-49 years). DHS surveys follow the same standard procedures - sampling, questionnaires, data collection, cleaning, coding and analysis which allows for crosscountry comparison. The survey employs a stratified two-stage sampling technique. The first stage involved the selecting of points or clusters (enumeration areas [EAs]). The second stage is the systematic sampling of households listed in each cluster or EA. All women in their reproductive age (15-49) who were usual of selected households or visitors who slept in the household on the night before the survey were interviewed. The response rate varied from $86.2 \%$ to $100.0 \%$ For the purpose of this, only women who had information on reproduction health decision-making were used $(N=84,486)$. Women gave oral and written consent. Ethical approval was given by individual national institutions review board and by ICF International institutional review board. Permission to use the data set was sort from MEASURE DHS. Data set is available to the public at www.measuredhs.org.

\section{Definition of variables \\ Outcome variables}

The outcome variable employed for this study was intimate partner violence. The outcome variable was derived from three questions "experienced any sexual violence?", "experienced any emotional violence?" and "experienced and physical violence?". The response categories of these variables were: "Yes" and "No". The 'Yes' responses were coded ' 1 ' and the 'No' responses were coded ' 0 '. An index was created with all the "Yes" and "No" answers with scores ranging from 0 to 3 . The score 0 was labelled as "No" and 1 to 3 was labelled as "Yes". A dummy variable was generated with ' 0 ' score being females who had not experienced any form of sexual or emotional or physical violence and ' 1 ' if females had experienced either sexual or emotional or physical violence.

\section{Explanatory variables}

The main explanatory variable, decision-making capacity, was derived from three questions "decision on personal health care", "decision on large household purchase" and "decision on visits to family or relatives". These response categories were recoded as "not alone $=0$ " and "alone $=1$ "). An index was created with all the "yes" and "no" answers with scores ranging from 0 to 3 . The score 0 and 1 were labelled as "no capacity" and 2 and 3 were labelled as "capacity". A dummy variable was generated with ' 0 ' score being females who did not have the capacity and ' 1 ' if females who had the capacity.

The other explanatory variables consisted of: residence, age, wealth status, education, religion, occupation, marital status, partner's education and country. Residence was categorized as urban and rural. Age was grouped in 5 - year interval: $15-19,20-24,25-29,30-34,35-39,40-44,45-49$. Wealth status was derived from the ownership of a variety of household assets and categorized as poorest, poorer, middle, richer and richest. Level of education and partner's education was captured as no education, primary, secondary and higher education. Religion was recoded as Christian, Muslims and Others. Religion was not available for Niger. Occupation was categorized as not working, working outside the home and working at home. Marital status was captured as married and cohabitation.

\section{Statistical analysis}

Descriptive and inferential statistics were conducted. Descriptive figures are reposted in percentages by countries. Univariate and multivariate logistic regression models used to investigate the relationship between the explanatory variables and the outcome variable. Two models were used to access the predictors of intimate partner violence. Model I looked at a bivariate analysis of the main independent variable, thus, decision-making capacity and the outcome variable. Model II looked at a bivariate analysis between decision-making capacity and the outcome variable and controlled for age and country. Model III adjusted for age and country by including them in the model together with all the other independent variables. This was done to find the association between all the independent variables, including age and country and the outcome variable. All frequency distributions were weighted whiles the survey command in Stata was used to adjust for the complex sampling structure of the data in the regression analyses. All results of the logistic analyses were presented as odds ratios (ORs) with $95 \%$ confidence intervals (CIs). 


\section{Results}

\section{Prevalence of IPV in sub-Saharan Africa}

The survey included a total of 84,486 women from 18 countries in Sub-Saharan Africa. Table 1 presents results on respondents who have ever experienced any sexual violence, any emotional violence, any physical violence and any sexual, emotional violence or physical violence.

On the whole, the percentage of women in who had experienced any sexual violence was 9.6\%, those who had experienced any emotional violence was 24.5\%, those who had experienced any physical violence was $26.4 \%$ and those who had experienced any sexual, emotional violence or physical violence was $37 \%$. Out of the 19 countries, women in Congo DR recorded the highest sexual violence $(24.4 \%)$ and Comoros recorded the lowest rate of sexual violence (1.6\%). A greater of percentage $(40.1 \%)$ of women in Cameroon had experienced any emotional violence and the country with the lowest percentage of women who had experienced any emotional violence was Comoros (7\%). With physical violence, Gabon had the highest prevalence (45.3\%) while Comoros had the lowest prevalence (4.9\%). Finally, $56.6 \%$ of women in Cameroon had experienced any sexual, emotional or physical violence and $9.4 \%$ of women in Comoros had experienced any sexual, emotional or physical violence (see Table 1).

\section{Decision-making capacity among women in sub-Saharan Africa}

Three variables were used to assess women decisionmaking capacity. They include the decision on personal health care, the decision on a large household purchase and the decision on visits to family or relatives. In general, $12.1 \%$ of women in Sub-Saharan Africa had decisionmaking capacity and $87.9 \%$ had no decision-making capacity (see Table 2). Further results indicate that, out of the 18 countries in Sub-Saharan Africa, Namibia had the greatest percentage of women with decision-making capacity (32.7\%), with Mali and Malawi having the least percentage of women with decision-making capacity (5.5\%).

\section{Univariate and multivariate logistic regression}

As shown in Table 3, the univariate and multivariate logistic regression analyses carried out between women decision-making capacity and background characteristics and IPV showed significant associations between decision-making capacity, age, country, religion, partners' education, occupation, marital status, education and wealth status and IPV. As shown in model I, II and III, results on women' decision-making capacity showed that women with decision-making capacity were more likely to experience IPV compared to those who had no decision-making capacity $[\mathrm{OR}=1.73 ; \mathrm{CI}=1.61-1.85]$,

Table 1 Experience of IPV among women in Sub-Saharan Africa

\begin{tabular}{|c|c|c|c|c|c|c|c|c|c|}
\hline \multirow[t]{2}{*}{ Country } & \multirow[t]{2}{*}{$\mathrm{N}^{*}$} & \multicolumn{2}{|c|}{$\begin{array}{l}\text { Experienced any } \\
\text { sexual violence }\end{array}$} & \multicolumn{2}{|c|}{$\begin{array}{l}\text { Experienced any } \\
\text { emotional violence }\end{array}$} & \multicolumn{2}{|c|}{$\begin{array}{l}\text { Experienced any } \\
\text { physical violence }\end{array}$} & \multicolumn{2}{|c|}{$\begin{array}{l}\text { Experienced any } \\
\text { sexual or emotional } \\
\text { or physical violence }\end{array}$} \\
\hline & & Number & Percent & Number & Percent & Number & Percent & Number & Percent \\
\hline Congo DR, 2013-2014 & 4758 & 1163 & 24.4 & 1661 & 34.9 & 2127 & 44.7 & 2676 & 56.2 \\
\hline Cote d'voire, 2011-2014 & 4356 & 230 & 5.3 & 818 & 18.8 & 1087 & 24.9 & 1357 & 31.2 \\
\hline Cameroon, 2011 & 3442 & 496 & 14.4 & 1382 & 40.1 & 1491 & 43.3 & 1950 & 56.6 \\
\hline Gabon, 2012 & 2791 & 396 & 14.2 & 901 & 32.3 & 1264 & 45.3 & 1512 & 54.2 \\
\hline Gambia, 2013 & 3161 & 70 & 2.2 & 446 & 14.1 & 584 & 18.5 & 773 & 24.4 \\
\hline Kenya, 2014 & 3613 & 421 & 11.7 & 1033 & 28.6 & 1221 & 33.8 & 1569 & 43.4 \\
\hline Comoros, 2012 & 1979 & 31 & 1.6 & 138 & 7.0 & 98 & 4.9 & 186 & 9.4 \\
\hline Mali, 2012-2013 & 2647 & 356 & 13.4 & 827 & 31.2 & 779 & 29.4 & 1155 & 43.6 \\
\hline Malawi, 2010 & 4517 & 801 & 17.7 & 1181 & 26.1 & 1058 & 23.4 & 1765 & 39.1 \\
\hline Mozambique, 2011 & 4843 & 351 & 7.2 & 1591 & 32.8 & 1454 & 30.0 & 2165 & 44.7 \\
\hline Nigeria, 2013 & 21,413 & 940 & 4.4 & 3884 & 18.1 & 2860 & 13.4 & 5017 & 23.4 \\
\hline Namibia, 2015 & 889 & 56 & 6.4 & 198 & 22.3 & 190 & 21.3 & 273 & 30.7 \\
\hline Rwanda, 2014-2015 & 1540 & 152 & 9.8 & 347 & 22.6 & 434 & 28.2 & 577 & 37.4 \\
\hline Sierra Leone, 2013 & 4023 & 283 & 7.1 & 1144 & 28.4 & 1751 & 43.5 & 2011 & 50.0 \\
\hline Chad, 2014-2015 & 3204 & 298 & 9.3 & 671 & 21.0 & 773 & 24.1 & 1029 & 32.1 \\
\hline Togo, 2013-2014 & 4778 & 318 & 6.7 & 1371 & 28.8 & 896 & 18.8 & 1642 & 34.4 \\
\hline Zambia, 2013-2014 & 7576 & 1194 & 15.8 & 1648 & 21.8 & 2786 & 36.8 & 3426 & 45.2 \\
\hline Zimbabwe, 2015 & 4952 & 570 & 11.5 & 1485 & 30.0 & 1445 & 29.2 & 2172 & 43.9 \\
\hline All countries & 84,486 & 8128 & 9.6 & 20,729 & 24.5 & 22,297 & 26.4 & 31,254 & 37.0 \\
\hline
\end{tabular}

${ }^{*}$ weighted $\mathrm{N}$ 
Table 2 Decision-making capacity among women in Sub-Saharan Africa

\begin{tabular}{|c|c|c|c|c|c|c|c|c|}
\hline \multirow[t]{2}{*}{ Country } & \multicolumn{2}{|c|}{$\begin{array}{l}\text { Decision on personal } \\
\text { healthcare }\end{array}$} & \multicolumn{2}{|c|}{$\begin{array}{l}\text { Decision on large } \\
\text { household purchase }\end{array}$} & \multicolumn{2}{|c|}{$\begin{array}{l}\text { Decision on visits to } \\
\text { family or relatives }\end{array}$} & \multicolumn{2}{|c|}{ Decision-making capacity } \\
\hline & Not alone (\%) & Alone (\%) & Not alone (\%) & Alone (\%) & Not alone (\%) & Alone (\%) & No capacity (\%) & Capacity (\%) \\
\hline Congo DR, 2013-2014 & 89.8 & 10.2 & 84.1 & 15.9 & 81.3 & 18.7 & 90.0 & 10.0 \\
\hline Cote d'voire, 2011-2014 & 89.9 & 10.1 & 91.1 & 8.9 & 81.5 & 18.5 & 91.2 & 8.9 \\
\hline Cameroon, 2011 & 84.4 & 15.6 & 83.8 & 16.2 & 77.1 & 22.9 & 86.1 & 13.9 \\
\hline Gabon, 2012 & 74.6 & 25.4 & 61.9 & 38.1 & 67.0 & 33.0 & 73.1 & 26.9 \\
\hline Gambia, 2013 & 74.6 & 25.4 & 94.6 & 5.5 & 81.7 & 18.3 & 86.0 & 14.0 \\
\hline Kenya, 2014 & 62.6 & 37.4 & 79.7 & 20.3 & 77.0 & 23.0 & 77.1 & 22.9 \\
\hline Comoros, 2012 & 81.2 & 18.8 & 75.1 & 24.9 & 72.7 & 27.3 & 79.0 & 21.0 \\
\hline Mali, 2012-2013 & 94.1 & 5.9 & 92.3 & 7.7 & 93.1 & 6.9 & 94.5 & 5.5 \\
\hline Malawi, 2010 & 81.8 & 18.2 & 90.6 & 9.4 & 82.4 & 17.6 & 94.5 & 5.5 \\
\hline Mozambique, 2011 & 78.9 & 21.1 & 87.2 & 12.8 & 83.3 & 16.7 & 86.0 & 16.0 \\
\hline Nigeria, 2013 & 93.7 & 6.3 & 94.5 & 5.6 & 92.3 & 7.7 & 94.8 & 5.2 \\
\hline Namibia, 2015 & 53.4 & 46.6 & 73.7 & 26.3 & 68.6 & 31.4 & 67.3 & 32.7 \\
\hline Rwanda, 2014-2015 & 79.3 & 20.7 & 89.5 & 10.6 & 83.7 & 16.3 & 87.3 & 12.7 \\
\hline Sierra Leone, 2013 & 92.5 & 7.5 & 92.8 & 7.2 & 90.8 & 9.2 & 93.7 & 6.3 \\
\hline Chad, 2014-2015 & 92.2 & 7.8 & 80.3 & 19.7 & 77.6 & 22.4 & 87.9 & 12.1 \\
\hline Togo, 2013-2014 & 88.8 & 11.2 & 85.9 & 14.1 & 83.7 & 16.3 & 90.0 & 10.0 \\
\hline Zambia, 2013-2014 & 68.4 & 21.6 & 88.5 & 11.5 & 79.6 & 20.4 & 85.0 & 15.0 \\
\hline Zimbabwe, 2015 & 65.4 & 34.6 & 72.8 & 27.2 & 73.0 & 27.0 & 74.3 & 25.7 \\
\hline All countries & 83.4 & 16.6 & 87.2 & 12.8 & 83.3 & 16.7 & 87.9 & 12.1 \\
\hline
\end{tabular}

$[\mathrm{OR}=1.49 ; \mathrm{CI}=1.42-1.55]$ and $[\mathrm{AOR}=1.35 ; \mathrm{CI}=1.35-$ 1.48] respectively. The odds of experiencing IPV was low among women 15-19 years compared to women in other age groups, with women aged 20-24 years having the highest odds of ever experienced IPV $[\mathrm{AOR}=1.41$; $\mathrm{CI}=1.32-1.51]$. In relation to country, women in Mali had the highest odds of ever experienced IPV compared to women in Congo DR [AOR $=1.50 ; \mathrm{CI}=1.34-1.67]$. However, the likelihood of ever experienced IPV was low among women in Comoros compared to women in Congo DR $[\mathrm{AOR}=0.17 ; \mathrm{CI}=0.15-0.21]$. Religion was also found to have an influence on women experience of IPV. Specifically, women who belong to other religious groups and Christians were more likely to IPV compared to those who were Muslims $[\mathrm{AOR}=1.73 ; \mathrm{CI}=1.65-$ $1.82]$ and $[\mathrm{AOR}=1.87 ; \mathrm{CI}=1.72-2.02]$ respectively. Further results also showed that women who have partners with no education $[\mathrm{AOR}=1.11 ; \mathrm{CI}=1.03-1.20]$, those whose partners had primary education [AOR = 1.34; $\mathrm{CI}=1.25-1.44]$ and those whose partners had secondary education $[\mathrm{AOR}=1.22 ; \mathrm{CI}=1.15-1.30]$ were more likely to IPV compared to those whose partners had higher education.

The odds of experiencing IPV were high among women who were employed compared to those who were unemployed $[\mathrm{AOR}=1.33 ; \mathrm{CI}=1.28-1.37$ ]. The likelihood of the occurrence of IPV was also high among women who were cohabiting compared to those who were married $[\mathrm{AOR}=1.16 ; \mathrm{CI}=1.10-1.21]$. Women with no education $[\mathrm{AOR}=1.37 ; \mathrm{CI}=1.24-1.51]$, those with primary education $[\mathrm{AOR}=1.65 ; \mathrm{CI}=1.50-1.82]$ and those with secondary education $[\mathrm{AOR}=1.50 ; \mathrm{CI}=1.37-1.64$ ] were more likely to experience IPV compared to those with higher education. Finally, women with poorest wealth status $[\mathrm{AOR}=1.28 ; \mathrm{CI}=1.20-1.37]$, those with poorer wealth status $[\mathrm{AOR}=1.24 ; \mathrm{CI}=1.17-1.32]$, those with middle wealth status $[\mathrm{AOR}=1.27 ; \mathrm{CI}=1.20-1.34]$ and those with richer wealth status $[\mathrm{AOR}=1.11 ; \mathrm{CI}=1.06-1.17]$ were more likely to IPV compared to women with richest wealth status.

\section{Discussion}

In this present study, our aim was to examine the association between women decision-making capacity and IPV among Women in Sub-Saharan Africa. We also looked at how socio-demographic factors influence IPV among Women in Sub-Saharan Africa. Our study found an overall prevalence of IPV of $37 \%$ and this is consistent with findings of previous studies on the prevalence of IPV in Sub-Saharan region [1, 25, 31]. These previous however included the general regions in Africa but our study considered only women in Sub-Saharan Africa. 
Table 3 Logistic regression on IPV and background characteristics among women in sub-Sahara Africa

\begin{tabular}{|c|c|c|c|c|}
\hline \multirow[t]{2}{*}{ Variable } & Proportions & Model I & Model II & Model III \\
\hline & $N=84,486(\%)$ & OR $(95 \% \mathrm{Cl})$ & OR $(95 \% \mathrm{Cl})$ & AOR $(95 \% \mathrm{Cl})$ \\
\hline \multicolumn{5}{|c|}{ Decision-making capacity } \\
\hline No capacity & 74,315 (87.9) & Ref & Ref & Ref \\
\hline Capacity & $10,271(12.1)$ & $1.73^{* * *(1.61-1.85)}$ & $1.49 * * *(1.42-1.55)$ & $1.35^{* * *}(1.35-1.48)$ \\
\hline \multicolumn{5}{|l|}{ Age } \\
\hline $15-19$ & 6078 & & Ref & Ref \\
\hline $20-24$ & 14,431 & & $1.33^{* * *}(1.25-1.42)$ & $1.30^{* * *}(1.22-1.39)$ \\
\hline $25-29$ & 18,007 & & $1.46^{* * *(1.37-1.56)}$ & $1.41^{* * *}(1.32-1.51)$ \\
\hline $30-34$ & 15,901 & & $1.45^{* * *(1.36-1.55)}$ & $1.39^{* * *}(1.30-1.49)$ \\
\hline $35-39$ & 13,095 & & $1.42^{* * *(1.32-1.52)}$ & $1.35^{* * *}(1.25-1.44)$ \\
\hline $40-44$ & 9484 & & $1.34^{* * *}(1.24-1.44)$ & $1.26^{* * *}(1.17-1.36)$ \\
\hline $45-49$ & 7490 & & $1.24^{* * *(1.15-1.34)}$ & $1.17^{* * *}(1.09-1.28)$ \\
\hline \multicolumn{5}{|l|}{ Country } \\
\hline Congo DR & 4758 & & Ref & Ref \\
\hline Cote d'voire & 4356 & & $0.36^{* * *}(0.33-0.39)$ & $0.49^{* * *}(0.45-0.54)$ \\
\hline Cameroon & 3442 & & $1.03(0.95-1.13)$ & $1.21^{* * *}(1.10-1.32)$ \\
\hline Gabon & 2791 & & $0.91^{* *}(0.83-1.00)$ & $0.93(0.85-1.03)$ \\
\hline Gambia & 3161 & & $0.30^{* * *}(0.27-0.33)$ & $0.64^{* * *}(0.58-0.71)$ \\
\hline Kenya & 3613 & & $0.53^{* * *}(0.48-0.58)$ & $0.61^{* * *}(0.56-0.66)$ \\
\hline Comoros & 1979 & & $0.08^{* * *}(0.07-0.09)$ & $0.17^{* * *}(0.15-0.21)$ \\
\hline Mali & 2647 & & $0.65^{* * *}(0.59-0.71)$ & $1.50^{* * *}(1.34-1.67)$ \\
\hline Malawi & 4517 & & $0.50^{* * *}(0.46-0.55)$ & $0.55^{* * *}(0.51-0.60)$ \\
\hline Mozambique & 4843 & & $0.66^{* * *}(0.60-0.71)$ & $0.77^{* * *}(0.71-0.84)$ \\
\hline Nigeria & 21,413 & & $0.27^{* * *}(0.25-0.28)$ & $0.41^{* * *}(0.39-0.44)$ \\
\hline Namibia & 889 & & $0.33^{* * *}(0.29-0.38)$ & $0.45^{* * *}(0.39-0.52)$ \\
\hline Rwanda & 1540 & & $0.45^{* * *}(0.40-0.51)$ & $0.42^{* * *}(0.37-0.47)$ \\
\hline Sierra Leone & 4023 & & $0.74^{* * *}(0.68-0.81)$ & $1.39^{* * *}(1.27-1.53)$ \\
\hline Chad & 3204 & & $0.30^{* * *}(0.28-0.33)$ & $0.57^{* * *}(0.51-0.63)$ \\
\hline Togo & 4778 & & $0.45^{* * *}(0.41-0.49)$ & $0.50^{* * *}(0.46-0.55)$ \\
\hline Zambia & 7576 & & $0.66^{* * *}(0.62-0.71)$ & $0.70^{* * *}(0.65-0.76)$ \\
\hline Zimbabwe & 4952 & & $0.56^{* * *}(0.51-0.60)$ & $0.66^{* * *}(0.60-0.71)$ \\
\hline \multicolumn{5}{|l|}{ Residence } \\
\hline Urban & $30,654(36.3)$ & & & Ref \\
\hline Rural & $53,832(63.7)$ & & & $0.88(0.85-0.92)$ \\
\hline \multicolumn{5}{|l|}{ Religion } \\
\hline Islam & $31,697(37.5)$ & & & Ref \\
\hline Christian & $49,068(58.1)$ & & & $1.73^{* * *}(1.65-1.82)$ \\
\hline Others & $3721(4.4)$ & & & $1.87^{* * *}(1.72-2.02)$ \\
\hline \multicolumn{5}{|c|}{ Partner's Education } \\
\hline No education & $25,090(29.7)$ & & & $1.11^{* *(1.03-1.20)}$ \\
\hline Primary & $23,164(27.4)$ & & & $1.34^{* * *}(1.25-1.44)$ \\
\hline Secondary & $38,159(33.3)$ & & & $1.22^{* *}(1.15-1.30)$ \\
\hline Higher & $8073(9.6)$ & & & Ref \\
\hline
\end{tabular}

Occupation 
Table 3 Logistic regression on IPV and background characteristics among women in sub-Sahara Africa (Continued)

\begin{tabular}{|c|c|c|c|c|}
\hline \multirow[t]{2}{*}{ Variable } & Proportions & Model I & Model II & Model III \\
\hline & $N=84,486(\%)$ & OR $(95 \% \mathrm{Cl})$ & OR $(95 \% \mathrm{Cl})$ & AOR $(95 \% \mathrm{Cl})$ \\
\hline Unemployed & $27,164(32.1)$ & & & Ref \\
\hline Employed & $57,322(67.9)$ & & & $1.33^{* * *}(1.28-1.37)$ \\
\hline \multicolumn{5}{|l|}{ Marital status } \\
\hline Married & $73,338(86.8)$ & & & Ref \\
\hline Cohabitation & $11,148(13.2)$ & & & $1.16^{* * *}(1.10-1.21)$ \\
\hline \multicolumn{5}{|l|}{ Education } \\
\hline No education & $31,043(36.7)$ & & & $1.37^{* * *}(1.24-1.51)$ \\
\hline Primary & $27,441(32.5)$ & & & $1.65^{* * *}(1.50-1.82)$ \\
\hline Secondary & $21,983(26.0)$ & & & $1.50^{* * *}(1.37-1.64)$ \\
\hline Higher & $4019(4.8)$ & & & Ref \\
\hline \multicolumn{5}{|l|}{ Wealth status } \\
\hline Poorest & $17,075(20.2)$ & & & $1.28^{* *}(1.20-1.37)$ \\
\hline Poorer & $17,271(20.5)$ & & & $1.24^{* *}(1.17-1.32)$ \\
\hline Middle & 16,552 (19.6) & & & $1.27^{* * *}(1.20-1.34)$ \\
\hline Richer & $16,904(20.0)$ & & & $1.11^{* *}(1.06-1.17)$ \\
\hline Richest & 16,684 (19.7) & & & Ref \\
\hline
\end{tabular}

${ }^{*} p<0.10{ }^{* *} p<0.05{ }^{* * *} p<0.001$ OR Odds Ratio

The comparison of the study results is, therefore, to be made with caution.

On women decision-making capacity, the current study used three variables (the decision on personal health care, the decision on a large household purchase and the decision on visits to family or relatives) and this was linked to women empowerment. It was revealed that the empowerment level of women in Sub-Saharan Africa is low (12.1\%). The results further revealed that out of the 19 countries in Sub-Saharan Africa, Namibian women were those who were more empowered (32.7\%) while Mali and Malawi had the least percentage of empowered women (5.5\%). The finding of our study in relation to the level of women empowerment mirrors the findings of Ameyaw et al. [32]. The differences in the level of women empowerment could also be due to the variations in policies and legislation that exist in countries in Sub-Saharan Africa.

Our data suggest that women who had the capacity to take decisions were more likely to experience IPV compared to those who did not have decision-making capacity. The positive association between women decisionmaking capacity and IPV is consistent with a current study by Cools and Kotsadam [4]. The finding still corroborates previous studies that found that the more a woman is empowered the more likely she is to suffer from IPV [25-27, 30]. The possible explanation for this is the fact that women who are more empowered are able to fight for their rights and will not accept men to fully dictate to them which could result in IPV. Another possible explanation is that in Africa, most cultures prefer women to be subordinated to men, but women who are more empowered do not solely depend on men for their survival and tend to resist some of the decisions of men which may bring about intimate partner violence. However, the findings are contrary to the findings of a Bangladeshi study where women empowerment is served as protective means to get rid of IPV [29].

The study revealed that women aged 15-19 years are less likely to report having ever experienced IPV compared with older women. Similar findings were obtained by Bazargan-Hejazi et al. [33] who found that younger women were less likely to report IPV compared to women in the ages 45 to 49 . Similarly, a study on women empowerment and spousal violence in relation to health outcomes in Nepal also identified that youngest women (15-19) are the least likely to report having ever experienced IPV compared with older women [34]. A likely explanation is that young women duration of exposure to the risk of spousal violence is less than that of older women. Hence, the likelihood of experiencing IPV is low among them. Furthermore, women in the older age groups tend to be less educated, have more children, and are more likely to have lower decision-making capacity than their slightly younger counterparts, hence are more likely to have higher levels of IPV. Older women are also more likely to have experienced spousal violence during their lifetime, compared to those aged 15-19 whose lifetime prevalence of IPV is likely to be lower.

Another key finding was the influence of religious affiliation on women experience of IPV in Sub-Saharan 
Africa. A number of studies have shown the association between religious affiliation and intimate partner violence $[35,36]$. In most cases, religious affiliation and groups can be social networks that involve the sharing of ideas and behaviours. It was shown from our study that, women who belonged to other religious groups and Christians were more likely to experience IPV compared to those who were Muslims. The findings are consistent with other studies such as Naved and Persson [35] and Ackerson et al. [36]. Christianity and other religious groups are sometimes associated with dogmatic views regarding gender inequality, the centrality of male dominance in various spheres of life in the home, and also the sanctity of family unity, that have the potential to be misinterpreted or exaggerated. The misinterpretation of these dogmatic views may bring about IPV against women. Furthermore, another reason for this finding could be that the Islamic religion has strict norms that may prohibit violence against women. Such norms relate to how women should be treated with diligence within the religion.

The study revealed that there was an inverse association between the educational level of a woman's partner and IPV. The odds of being abused decreased with an increasing level of women partners' level of education. Women who have partners with no formal education, those whose partners had primary education and those whose partners had secondary education were more likely to experience IPV compared to those whose partners had higher education. The possible explanation to this is that those whose partners have higher education are exposed to training and they value the need to respect the rights and freedom of other people. Again, the education that they receive makes them get rid of certain socio-cultural practices that put limitations on the value of women. The relationship between spousal educational level and IPV is not consistent in literature. Our findings are consistent with the findings of studies that showed that as a partner's level of education increases the risk of experiences sexual or emotional violence decreases $[28,37,38]$. Nonetheless, the findings do not corroborate the findings of Burazeri et al. [39]. In some instances, some men who are less educated might have low self-esteem and this may lead to the tendency of being violent against their partners [28].

The odds of experiencing IPV were high among women who were employed compared to those who were unemployed. This finding can be explained by the fact that if women attain a higher level of formal education, they are also empowered economically. As a result, they can compete with men for available positions and jobs that are available in society and this does not make them rely on men for their basic needs in life. Again, educational level of a woman can predict the type of occupation she will take up. Because occupation is one of the determinants of empowerment, women who are employed tend to resist being controlled by their men. Also, the study found that women with no education, those with primary education and those with secondary education were more likely to experience IPV compared to those with higher education. It is a well-established fact that if women are more educated, due to the exposure they obtain, it can let them fight for their rights and that of other marginalized women in their communities. They can help champion the fight against indiscrimination and bad socio-cultural practices that are against women. The findings of this current study are congruent to that of Hindin, Kishor and Ansara [40], who found education as a protective factor against sexual or emotional violence in Bolivia, Kenya and Zimbabwe. It can, therefore, be assumed that encouraging more women to be educated can reduce the prevalence of IPV.

Furthermore, in our study, there was a significant association between marital status and IPV. The results showed that the likelihood of the occurrence of IPV was high among women who were cohabiting compared to those who were married. This could be clarified in the sense that those in marriage usually understand each other and are more likely to compromise on certain issues which brings less conflict in their matrimonial homes. The findings are not consistent with the findings of that currently married women are the most likely to report physical or sexual violence in the last 12 months [41].

In our analysis, wealth status showed a statistically significant influence on IPV. Specifically, women with poorest wealth status, those with poorer wealth status, those with middle wealth status and those with richer wealth status were more likely to experience IPV compared to women with richest wealth status. This means that IPV decreases when there is an increase in wealth status. The relationship between wealth status and IPV is however not clear. Some studies have found a positive relationship while others have found an inverse relationship. The findings of this present study are similar to other studies conducted in SubSaharan Africa [42]. However, the findings of this current study deviated from that of Bamiwuye and Odimegwu [43] in their study in Zambia and Mozambique and Okemgbo, Omideyi and Odimegwu [44] in their study in Nigeria.

The study had its strength from the large data used from different countries in Sub-Saharan Africa. The use of nationally representative surveys (DHS) and the use of stratified two- stage sampling technique made it possible to obtain samples that are highly representative of the target populations. The use of a large sample size and the national representative nature of the data make conclusions from our study valid. Nonetheless, the study sample was limited to only women in their reproductive age group (15-49 years old) and did not consider women below 15 years and those above 49 years. Again, the cross-sectional nature of the study does not make it 
possible to make any causal inference but rather only associations can be made. The data also relies mainly on a verbal report that was given by the women. Another limitation of the study is the use of lifetime prevalence instead of prevalence within the last 12 months. This affected the odds of IPV among respondents, especially with respect to age. Finally, since data was obtained using a purely quantitative approach, in-depth information which could have been obtained using a qualitative approach was not considered.

\section{Conclusion}

African women are burdened with IPV in various stages of their life course, especially during their reproductive ages. Our study has examined the association between women decision-making capacity and IPV among Women in Sub-Saharan Africa. It was found that the prevalence of IPV is Sub-Saharan Africa is within the range of prevalence found in previous studies that have been conducted in Africa. In Sub-Saharan Africa, women in Cameroun experienced the highest lifetime prevalence of IPV. Our study also showed a very low level of women decisionmaking capacity in Sub-Saharan Africa. The country with the high level of decision-making capacity in Sub-Saharan Africa even had a percentage of decision-making capacity far below $50 \%$ of the women in their reproductive age group. Though related socio-demographic characteristics and women decision making capacity provided an explanation of IPV among women in Sub-Saharan Africa, there were differences in relation to how each socio-demographic variable predisposed women to IPV in Sub-Saharan Africa.

The odds of women experiencing IPV was higher among women who belonged to other religious groups, whose partners had primary education, women who were employed, women who were cohabiting, women with primary education and those with middle wealth. The findings thus clearly indicate the need for governments in Africa to invest more in female child education since an inverse relationship between education and IPV was identified. There is also the need for timely screening of women for physical violence but also since that was the most prevalent type of violence women experienced in Sub-Saharan Africa. Although little evidence shows that screening alone has the propensity to reduce the prevalence of IPV, when this is coupled with education of males on the effects of IPV, it is more likely to reduce the occurrence of IPV in future. The risk of IPV among women who are empowered and those who are employed can be reduced by sensitizing women to understand the need to be submissive no matter their status in society. Chastisement that comes with offenders of IPV should be carried out and enforced so as to deter other people from engaging in such acts.

\section{Acknowledgements}

We acknowledge Measure DHS for providing us with the data upon which the findings of this study were based.

\section{Authors' contributions}

KSD and BOA conceived the study. KSD designed and performed the analysis and the write up of data and methods. KSD, AS and BOA designed the first draft of the manuscript. KSD, AS and BOA revised the manuscript for intellectual content and gave consent for the version to be published. All authors read and approved the final manuscript.

\section{Ethics approval}

All procedures performed in studies involving human participants were in accordance with the ethical standards of the institutional and/or national research committee and with the 1964 Helsinki declaration and its later amendments or comparable ethical standards. Consent to participate is not applicable to our study since it utilised DHS data.

\section{Consent for publication}

Not applicable.

\section{Competing interests}

The authors declare that they have no competing interests.

\section{Publisher's Note}

Springer Nature remains neutral with regard to jurisdictional claims in published maps and institutional affiliations.

\section{Author details}

${ }^{1}$ Department of Health, Physical Education and Recreation, University of Cape Coast, Cape Coast, Ghana. ${ }^{2}$ Department of Population and Health, University of Cape Coast, Cape Coast, Ghana.

Received: 9 October 2017 Accepted: 4 January 2018

Published online: 29 January 2018

\section{References}

1. Devries KM, Mak JY, Garcia-Moreno C, Petzold M, Child JC, Falder G, et al. The global prevalence of intimate partner violence against women. Science. 2013;340(6140):1527-8.

2. Abramsky T, Watts CH, Garcia-Moreno C, Devries K, Kiss L, Ellsberg M, et al. What factors are associated with recent intimate partner violence? Findings from the WHO multi-country study on women's health and domestic violence. BMC Public Health. 2011;11(1):109-26.

3. Durevall $D$, Lindskog A. Intimate partner violence and HIV in ten subSaharan African countries: what do the demographic and health surveys tell us? Lancet Glob Health. 2015;3(1):34-43.

4. Cools S, Kotsadam A. Resources and intimate partner violence in subSaharan Africa. World Dev. 2017;95:211-30.

5. García-Moreno C, Pallitto C, Devries K, Stöckl H, Watts C, Abrahams N. Global and regional estimates of violence against women: prevalence and health effects of intimate partner violence and non-partner sexual violence. Geneva: World Health Organization; 2013.

6. Campbell JC. Health consequences of intimate partner violence. Lancet. 2002;359(9314):1331-6.

7. Jankey O, Próspero M, FawsoSn P. Mutually violent attitudes: effects on intimate partner violence and mental health symptoms among couples in Botswana, Africa. J Aggression, Confl Peace Res. 2011;3(1):4-11.

8. Pallitto CC, García-Moreno C, Jansen HA, Heise L, Ellsberg M, Watts C. Intimate partner violence, abortion, and unintended pregnancy: results from the WHO multi-country study on Women's health and domestic violence. Int J Gynecol Obstet. 2013;120(1):3-9.

9. Salazar M, San Sebastian M. Violence against women and unintended pregnancies in Nicaragua: a population-based multilevel study. BMC Womens Health. 2014;14(1):26-35.

10. Emenike E, Lawoko S, Dalal K. Intimate partner violence and reproductive health of women in Kenya. Int Nurs Rev. 2008;55(1):97-102.

11. Stöckl H, Filippi V, Watts C, Mbwambo JK. Induced abortion, pregnancy loss and intimate partner violence in Tanzania: a population-based study. BMC Pregnancy Childbirth. 2012;12(1):12-20. 
12. Hathaway JE, Willis G, Zimmer B, Silverman JG. Impact of partner abuse on women's reproductive lives. J Am Med Wom Assoc. 2004;60(1):42-5.

13. Seth $P$, Raiford $J$, Robinson LS, Wingood GM, DiClemente RJ. Intimate partner violence and other partner-related factors: correlates of sexually transmissible infections and risky sexual behaviours among young adult African American women. Sex Health. 2010;7(1):25-30.

14. Weiss HA, Wasserheit JN, Barnabas RV, Hayes RJ, Abu-Raddad LJ. Persisting with prevention: the importance of adherence to HIV prevention. Emerg Themes Epidemiol. 2008;5(1):8-15.

15. Morrell R, Jewkes R, Lindegger G. Hegemonic masculinity/masculinities in South Africa: culture, power, and gender politics. Men Masculinities. 2012;15(1):11-30.

16. United Nations. Taking violence against women in Africa seriously. 2012, Retrieved from http://www.un.org/africarenewal/magazine/special-editionwomen-2012

17. Jewkes R, Morrell R. Gender and sexuality: emerging perspectives from the heterosexual epidemic in South Africa and implications for HIV risk and prevention. J Int AIDS Soc. 2010;13(1):6-13.

18. Boonzaier F. Woman abuse in South Africa: a brief contextual analysis. Feminism Psychol. 2005;15(1):99-103.

19. Koenig MA, Ahmed S, Hossain MB, Mozumder AKA. Women's status and domestic violence in rural Bangladesh: individual-and community-level effects. Demography. 2003;40(2):269-88.

20. Uthman OA, Lawoko S, Moradi T. Factors associated with attitudes towards intimate partner violence against women: a comparative analysis of 17 sub-Saharan countries. BMC Int Health Hum Rights. 2009;9(1):9-14

21. Boonzaier F, de La Rey C. "He's a man, and I'm a woman" cultural constructions of masculinity and femininity in south African Women's narratives of violence. Violence Against Women. 2003;9(8):1003-29.

22. McCloskey LA, Boonzaier F, Steinbrenner SY, Hunter T. Determinants of intimate partner violence in sub-Saharan Africa: a review of prevention and intervention programs. Partner Abuse. 2016;7(3):277-307.

23. Kabeer N. Gender equality and women's empowerment: a critical analysis of the third-millennium development goal 1. Gend Dev. 2005;13(1):13-24.

24. Upadhyay UD, Gipson JD, Withers M, Lewis S, Ciaraldi EJ, Fraser A, et al. Women's empowerment and fertility: a review of the literature. Soc Sci Med. 2014;115:111-20.

25. Jewkes R, Levin J, Penn-Kekana L. Risk factors for domestic violence: findings from a south African cross-sectional study. Soc Sci Med. 2002;55(9):1603-17.

26. Vyas $S$, Watts $C$. How does economic empowerment affect women's risk of intimate partner violence in low and middle-income countries? A systematic review of published evidence. J Int Dev. 2009;21(5):577-602.

27. Rahman M, Hoque MA, Makinoda S. Intimate partner violence against women: is women empowerment a reducing factor? A study from a national Bangladeshi sample. J Fam Violence. 2011;26(5):411-20.

28. Schuler SR, Lenzi R, Badal SH, Bates LM. Women's empowerment as a protective factor against intimate partner violence in Bangladesh: a qualitative exploration of the process and limitations of its influence. Violence Against Women. 2017;23(9):1100-21.

29. Naved RT, Persson LÅ. Factors associated with spousal physical violence against women in Bangladesh. Stud Fam Plan. 2005;36(4):289-300.

30. Groves AK, Moodley D, McNaughton-Reyes L, Martin SL, Foshee V, Maman S. Prevalence, rates and correlates of intimate partner violence among south African women during pregnancy and the postpartum period. Matern Child Health J. 2015;19(3):487-95.

31. Ameyaw EK, Appiah F, Agbesi CS, Kannor P. Contraceptive use in Ghana: what about women empowerment? Advances Sex Med. 2016;7(1):44-64.

32. Bazargan-Hejazi S, Medeiros S, Mohammadi R, Lin J, Dalal K. Patterns of intimate partner violence: a study of female victims in Malawi. J Inj Violence Res. 2013;5(1):38-50.

33. Tuladhar S, Khanal KR, Lila KC, Ghimire PK, Onta K. Women empowerment and spousal violence in relation to health outcomes in Nepal: further analysis of the 2011 Nepal demographic and health survey. p. 2013.

34. Warren, P. The relationship between religiousness and intimate partner violence risk and protective factors. (doctoral dissertation). 2015, Retrieved from http://scholarcommons.sc.edu/etd/3635.

35. Cunradi CB, Caetano R, Schafer J. Religious affiliation, denominational homogamy, and intimate partner violence among US couples. J Sci Study Relig. 2002;41(1):139-51.

36. Rapp D, Zoch B, Khan MMH, Pollmann T, Krämer A. Association between the gap in spousal education and domestic violence in India and Bangladesh. BMC Public Health. 2012;12(1):467.
37. Koenig MA, Stephenson R, Ahmed S, Jejeebhoy SJ, Campbell J. Individual and contextual determinants of domestic violence in North India. Am J Public Health. 2006;96(1):132-8.

38. Ackerson LK, Kawachi I, Barbeau EM, Subramanian SV. Effects of individual and proximate educational context on intimate partner violence: a populationbased study of women in India. Am J Public Health. 2008;98(3):507-14.

39. Burazeri G, Roshi E, Jewkes R, Jordan S, Bjegovic V, Laaser U. Factors associated with spousal physical violence in Albania: cross-sectional study. BMJ. 2005;331(7510):197-201.

40. Hindin MJ, Kishor S, Ansara DL. Intimate partner violence among couples in 10 DHS countries: predictors and health outcomes, DHS Analytical Studies No. 18. Calverton: Macro International Inc; 2008.

41. Chakwana CD, National Statistical Office (Malawi). Malawi demographic and health survey 2004. Final. Calverton: NSO and ORC Macro; 2005.

42. Kishor S. A focus on gender: collected papers on gender using DHS data. Calverton: ORC Macro; 2005.

43. Bamiwuye SO, Odimegwu C. Spousal violence in sub-Saharan Africa: does household poverty-wealth matter? Reprod Health. 2014;11(1):45-55.

44. Okemgbo CN, Omideyi AK, Odimegwu CO. Prevalence, patterns and correlates of domestic violence in selected Igbo communities of Imo state, Nigeria. Afr J Reprod Health. 2002;6:101-14.

\section{Submit your next manuscript to BioMed Central and we will help you at every step:}

- We accept pre-submission inquiries

- Our selector tool helps you to find the most relevant journal

- We provide round the clock customer support

- Convenient online submission

- Thorough peer review

- Inclusion in PubMed and all major indexing services

- Maximum visibility for your research

Submit your manuscript at www.biomedcentral.com/submit
Biomed Central 